\title{
Clinical evaluation of the oral gonadotropin-releasing hormone-antagonist elagolix for the management of endometriosis-associated pain
}

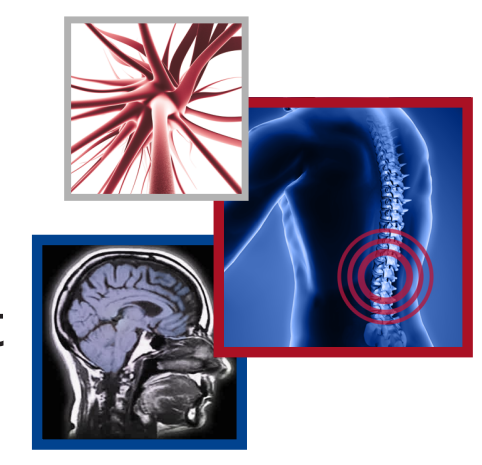

\author{
Hugh S Taylor*,1, Erica C Dun ${ }^{1} \&$ Kristof Chwalisz ${ }^{2}$ \\ ${ }^{1}$ Yale School of Medicine, 333 Cedar Street, New Haven, CT 06511, USA \\ ${ }^{2}$ AbbVie Inc., 1 North Waukegan Road, Bldg. AP4A-3, North Chicago, IL 60064, USA \\ *Author for correspondence: hugh.taylor@yale.edu
}

\section{Practice points}

- Endometriosis is a chronic, debilitating, inflammatory disease affecting $6-10 \%$ of women of reproductive age.

- Endometriosis is associated with chronic pelvic pain symptoms.

- Endometriosis-associated pain can lead to central sensitization.

- Estrogen dominance, in conjunction with progesterone resistance, plays a pivotal role in endometriosis by promoting the establishment and progression of the disease.

- Estrogens promote the implantation of endometrial tissue into the peritoneum, stimulate angiogenesis and neurogenesis in the lesions, and enhance local and systemic inflammation.

- Elagolix is a novel, nonpeptide, orally active gonadotropin-releasing hormone receptor antagonist that has recently been approved by the US FDA for the management of moderate to severe endometriosis-associated pain.

- Elagolix competitively inhibits gonadotropin-releasing hormone receptors in the pituitary gland and leads to a rapid and dose-dependent reduction in circulating gonadotropins and ovarian sex hormones, including estradiol.

- The Phase III program consisted of two large, multicenter, double-blind, randomized, placebo-controlled, 6-month trials (Elaris Endometriosis I and II [Elaris EM-I and Elaris EM-II]) with two elagolix doses (150 mg once daily and $200 \mathrm{mg}$ twice daily) and two double-blind, randomized, 6-month extension studies in women with endometriosis-associated pain (Elaris EM-III and Elaris EM-IV).

- Both higher and lower doses of elagolix were effective in improving dysmenorrhea and nonmenstrual pelvic pain during a 6-month period in the placebo-controlled Phase III trials (Elaris EM-I and Elaris EM-II).

- Long-term extension studies showed sustained reductions in dysmenorrhea, nonmenstrual pelvic pain and dyspareunia (Elaris EM-III and Elaris EM-IV).

Endometriosis is an estrogen-dependent chronic inflammatory disease associated with pelvic pain symptoms that are often severe, mainly dysmenorrhea, nonmenstrual pelvic pain and dyspareunia. This condition is also associated with peripheral and central sensitization. The current medical treatment options for endometriosis-associated pain are limited. Recently, the US FDA approved the novel, oral, nonpeptide gonadotropin-releasing hormone antagonist elagolix for the management of moderate to severe endometriosis-associated pain. Elagolix produces dose-dependent estrogen suppression, from partial suppression at lower doses to nearly full suppression at higher doses. This review article summarizes the current understanding of the pathophysiology of endometriosis, with a focus on the role of estrogen and the mechanisms of pain symptoms, and reviews the clinical development of elagolix in women with endometriosis-associated pain.

First draft submitted: 6 March 2019; Accepted for publication: 29 July 2019; Published online: 22 August 2019

Keywords: chronic pelvic pain • dysmenorrhea • dyspareunia • elagolix • endometriosis • endometriosis-associated chronic pain • estradiol • estrogen suppression • GnRH antagonist • nonmenstrual pelvic pain

Endometriosis is a debilitating, estrogen-dependent, inflammatory disease that affects $6-10 \%$ of women of reproductive age [1,2]. It is characterized by the presence of endometrium-like tissue outside the uterine cavity, most commonly on proximal pelvic organs and peritoneum, but can be found adherent to and invading into viscera 
throughout the body. The major clinical sequelae of the disease are chronic pelvic pain and infertility. The pelvic pain symptoms include dysmenorrhea, nonmenstrual pelvic pain (NMPP), dyspareunia and less commonly, dyschezia, dysuria and other pain symptoms [1]. Endometriosis-associated pain can be severe and lead to decreased quality of life and economic burden. In addition, deep dyspareunia can cause substantial psychological and relational distress [3]. The economic burden of endometriosis is substantial and affects women with direct medical costs, such as hospitalization, multiple surgeries, office visits and loss of work productivity, which is double that of healthcare costs [4-7]. In fact, the economic burden of endometriosis is comparable with that of other chronic diseases, such as diabetes, Crohn's disease and rheumatoid arthritis [6,8]. Laparoscopy has long been considered the 'gold standard' method of diagnosing endometriosis. However, there is a delay ranging from 5 to 9 years between symptom onset and definitive diagnosis of endometriosis by laparoscopy, depending on country and healthcare settings, which have been shown to be associated with reduced health-related quality of life [5,9].

The etiology of endometriosis is largely unknown, and its pathogenesis is complex and includes retrograde menstruation, genetic and environmental factors, progesterone resistance, local and systemic immunologic dysfunction and inflammation, and stem cell differentiation $[2,10]$. Estrogen, in conjunction with progesterone resistance, plays a pivotal role in these processes by promoting the establishment and progression of the disease [1,2].

Surgery and medical therapy are the two cornerstones of endometriosis management. Although surgery improves fertility in women with endometriosis and can lead to improvement in pain [11], at least $50-75 \%$ of women need analgesics or hormonal treatments because of pain recurrence within $2-5$ years after surgery $[12,13]$. The recurrence of pain after surgery might be due to either incomplete resection of the lesions or disease recurrence, and radical surgery (i.e., hysterectomy with oophorectomy) is often used as the last option [14]. Therefore, women with endometriosis-associated pain require long-term medical treatments until menopause, most commonly repeated cycles of various hormonal therapies often in combination with analgesics [1]. Nonsteroidal anti-inflammatory drugs (NSAIDs), progestins and estradiol- and progestin-containing combined oral contraceptives (COCs) are typically used as first-line therapies for endometriosis-associated pain [11]. Second-line therapies include injectable depot formulations of gonadotropin-releasing hormone $(\mathrm{GnRH})$ agonists, such as leuprolide acetate (LA), depot progestins (depot medroxyprogesterone acetate [DMPA]) and opioids [1,11]. However, these treatment options are limited and have shortcomings, such as limited efficacy (COCs, NSAIDs), tolerability issues including unacceptable irregular bleeding, bloating and weight gain (depot progestins), severe hypoestrogenic side effects ( $\mathrm{GnRH}$ agonists, aromatase inhibitors) and addiction risk (opioids) $[11,15,16]$. Hormonal therapy is effective in reducing endometriosisassociated pain, but response to different hormonal agents is highly variable and unpredictable. As a result, multiple trials of medications are frequently used, which place significant burden on patients. Oral contraceptives and NSAIDs are effective in reducing dysmenorrhea, but there is less evidence regarding their efficacy for NMPP and dyspareunia [17]. In addition, women with endometriosis develop progesterone resistance, which may explain failure of progestin-containing therapies, including COCs [18]. Although GnRH agonists (e.g., LA) are effective in reducing dysmenorrhea and NMPP [19], they induce profound estrogen suppression associated with progressive bone loss. Therefore, their use is restricted to 6 months without add-back therapy. However, according to the 'estrogen threshold hypothesis', which is based on differences in tissue sensitivity to estrogen, full estrogen suppression may not be needed to control endometriosis-associated pain and estrogen could be partially suppressed to a level that is sufficient to control pain but minimizes hypoestrogenic effects, including vasomotor symptoms and bone loss [20].

In July 2018, the US FDA approved elagolix 150 and $200 \mathrm{mg}$, a novel, oral GnRH antagonist, for the management of moderate to severe endometriosis-associated pain, the first new chemical entity for the treatment of endometriosis since the approval of LA in 1999. The recommended duration of treatment for women with normal liver function or mild hepatic impairment is 24 months for elagolix $150 \mathrm{mg}$ once daily (QD) and 6 months for elagolix $200 \mathrm{mg}$ twice daily (BID) [21].

Elagolix is an oral, nonpeptide GnRH antagonist. Both injectable and oral GnRH antagonists competitively inhibit GnRH receptors in the pituitary gland and lead to a rapid reduction in circulating gonadotropins and ovarian sex hormones, including estradiol [22]. This mechanism is different from that of GnRH agonists, which after an initial stimulatory phase desensitize GnRH receptors in the pituitary and subsequently cause cessation of pituitary gonadotropin production and full suppression of estradiol to levels that are equivalent to those associated with bilateral oophorectomy (Figure 1) [23]. In contrast to GnRH agonists, there is also a rapid cessation of hormonal suppression after stopping $\mathrm{GnRH}$ antagonist treatment. Therefore, oral $\mathrm{GnRH}$ antagonists provide a potential for adjusting the dose to balance efficacy and safety, which cannot be achieved with injectable GnRH antagonists and has not been clinically implemented with injectable GnRH antagonists. Elagolix produces dose-dependent estrogen 


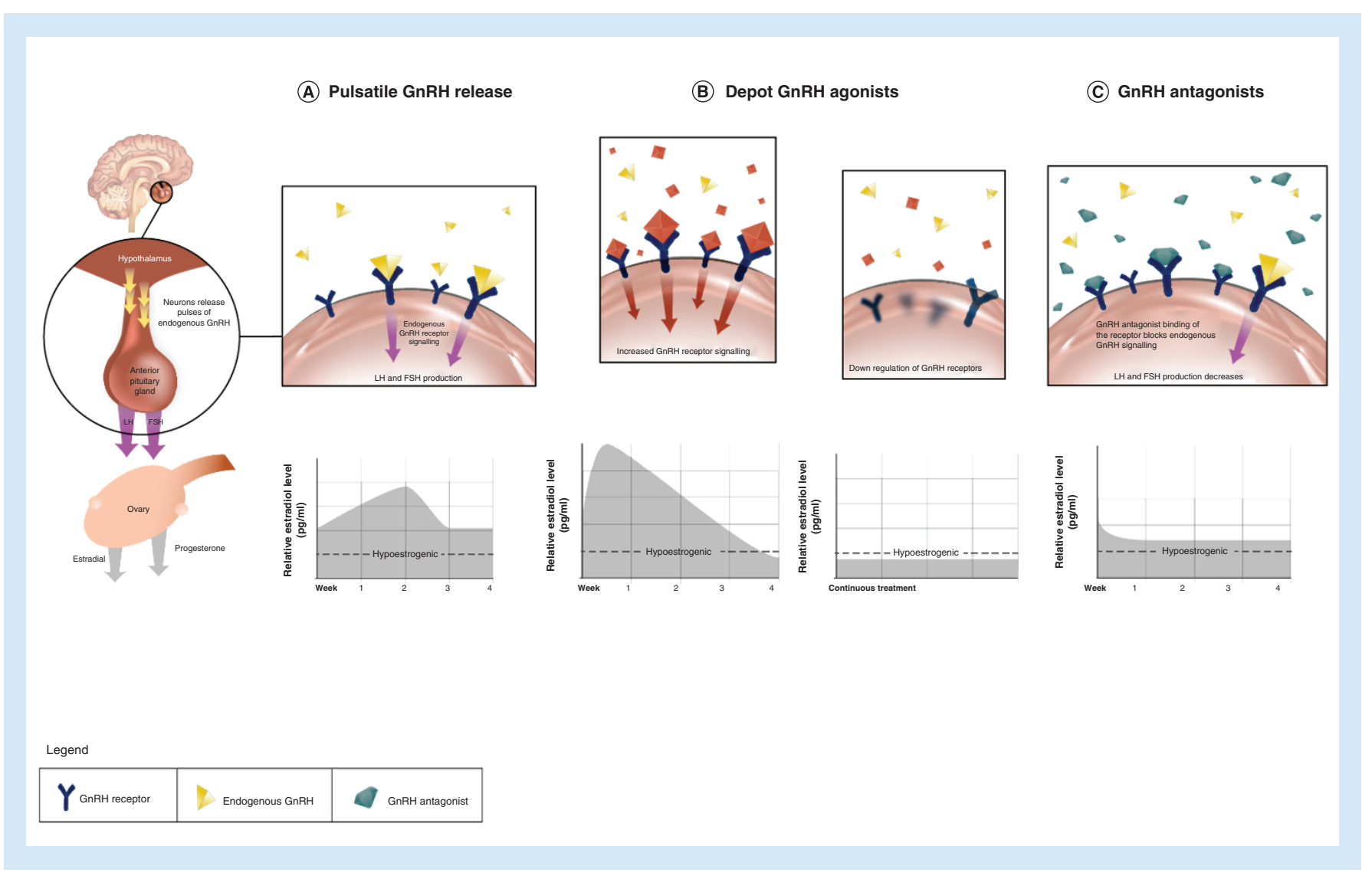

Figure 1. Mechanism of action of gonadotropin-releasing hormone antagonists versus depot gonadotropin-releasing hormone agonists. The figures in the upper level present the interaction of native GnRH (A), depot GnRH agonists (B) and GnRH antagonists (C) with the GnRH-R in the pituitary gland. The corresponding figures in the lower level present relative estradiol suppression. (A) Native $\mathrm{GnRH}$ is released in a pulsatile manner from the hypothalamus. The frequency of GnRH pulses regulates cyclic changes in gonadotropins (LH, FSH) and estradiol concentrations during the cycle. (B) Depot GnRH agonists initially stimulate the HPO axis, which results in a transient hormonal flare. Continued stimulation of GnRH-R consequently leads to their desensitization and profound suppression and profound estradiol suppression. (C) GnRH antagonists competitively bind to GnRH-R and produce rapid and dose-dependent suppression of the HPO axis, which results in a partial estradiol suppression at lower doses to nearly full suppression at higher doses. FSH: Follicle-stimulating hormone; GnRH: Gonadotropin-releasing hormone; GnRH-R: GnRH receptor; HPO: Hypothalamo-pituitary-ovarian; LH: Luteinizing hormone.

suppression, from partial suppression at lower doses to nearly full, but not complete, suppression at higher doses. The objectives of this review are to summarize the pathogenesis and pathophysiology of endometriosis, with a focus on the role of estrogen in this disease, discuss the mechanisms of pain symptoms and review the discovery and clinical development of elagolix for the management of endometriosis-associated pain.

\section{Pathogenesis, pathophysiology \& mechanism of pain in endometriosis}

\section{Pathogenesis}

Several theories have been developed to clinically explain how endometriosis implants in proximal pelvic organs and distant visceral organs. However, the actual pathogenesis of endometriosis remains uncertain.

Among the earliest and most widely accepted theories on the pathogenesis of endometriosis is Sampson's theory of retrograde menstruation [24-27]. Other theories include the lymphovascular metastasis theory [28,29] and the stem cell theory, which is based on dysregulation of endometrial stem cells implanting and generating ectopic endometrium via retrograde menstruation containing endometrial stem/progenitor cells [30] and via a circulating source of stem/endometrial progenitor cells [31,32].

Endometriosis is a complex disease caused by multiple variants and environmental factors, with approximately $50 \%$ of risk due to genetic factors [33,34]. Molecular techniques, including genome-wide association studies (GWAS) 
and family-based linkage studies, have identified several candidate genes located near known loci related to the development and regulation of female reproductive organs, including genes involved in sex steroid hormone pathways. A recent meta-analysis of 11 GWAS provided evidence for ten independent loci significantly associated with endometriosis risk, particularly at stage III/IV [35]. However, GWAS are accumulating evidence of common, 'old' genetic variants with the modest effect size and have been able to explain only a fraction of genetic risks to date. Family-based linkage studies using whole exome or genome sequencing showed promise to identify rare variants with high effect size associated with endometriosis risk [36]. In addition, autosomal cancer-associated mutations, including KRAS mutation, have been found in endometriotic lesions [37], showing further complexity of this disease.

\section{Pathophysiology \& the role of estrogen}

Supported by molecular and clinical evidence, estrogen, in conjunction with progesterone resistance, plays a pivotal role in endometriosis by promoting the establishment and progression of the disease. Estrogen promotes implantation of endometrial tissue into the peritoneum, stimulates angiogenesis and neurogenesis in the lesions, as well as enhances local and systemic inflammation $[1,2]$.

Both estrogen receptor $\alpha(E R \alpha)$ and estrogen receptor $\beta(E R \beta)$ are expressed in endometriotic lesions. However, $\mathrm{ER} \alpha$ levels are lower and ER $\beta$ are higher compared with normal endometrium [38]. ER $\beta$ seems to play a unique role in the progression of endometriosis by preventing the action of TNF- $\alpha$ induced apoptotic machinery and enhancing adhesion and proliferation of endometriotic cells [39]. It may also contribute to progesterone resistance in women with endometriosis [40].

Coordinated vasculogenesis and neurogenesis within the endometriosis lesion and its microenvironment are believed to support implantation and proliferation. Estrogen promotes survival of the endometriosis implants though several pathways involving nuclear and extranuclear ER signaling [41]. Estrogen also stimulates the production of inflammatory cells and cytokines that damage the mesothelium and facilitate adherence [2]. Estrogen has been found to increase levels of NGF, a major neurotrophic growth factor [42]. NGF expression is greater in peritoneal, ovarian and rectovaginal endometriosis than in eutopic endometrium [43].

Endometriosis is also characterized by an increased local production of estradiol (E2) and prostaglandin $\mathrm{E}_{2}\left(\mathrm{PGE}_{2}\right)$ by autoregulatory positive feedback mechanisms, which further stimulate disease progression [2,44]. Specifically, $\mathrm{PGE}_{2}$ stimulates both the aromatase and the steroidogenic acute regulatory protein, which regulates the first step in local estrogen biosynthesis (i.e., the entry of cholesterol into the mitochondrion) [2]. Both aromatase levels and activity are increased selectively in endometriotic cells but not eutopic endometrial stromal cells [45]. Aromatase, one of the key enzymes that converts cholesterol to estrone (E1), is stimulated to produce more E2 and $\mathrm{PGE}_{2}$, resulting in a positive feedback loop. These findings support the ability of endometriosis lesions to independently elevate the estrogen level in their microenvironment and proliferate.

Progesterone resistance also plays an important role in the establishment and progression of endometriosis [1]. Since progesterone is the major hormone suppressing estrogen-induced endometrial proliferation and inflammation, a decrease in progesterone action contributes to estrogen dominance in endometriosis. The mechanism of progesterone resistance is still unclear, but local and systemic inflammation, decrease in tissue progesterone receptor and ER $\alpha$ expression with concomitant increase in ER $\beta$ expression, as well as aberrant expression of nuclear receptor coregulators, have been implicated in this phenomenon $[39,40,46]$. Progesterone resistance may be important clinically, because it was shown that progesterone receptor status in endometriotic lesions predicts response to progestin therapy [18]. Thus, progesterone resistance may explain why some women became resistant to initial therapy with COCs or progestins. Additionally, in endometriotic tissues, progesterone fails to induce epithelial $17 \beta$-hydroxysteroid dehydrogenase type- 2 expression [47]. This enzyme typically metabolizes the biologically active E2 to E1. Inactivity of 17/-hydroxysteroid dehydrogenase type-2 results in deficient metabolism of E2 and elevated levels of E2 locally [48]. Elevated levels of E2 in the microenvironment of the endometriosis lesion promote proliferation by mechanisms previously described.

The role of inflammation and evasion from immune clearance in the pathogenesis of endometriosis cannot be overstated. Evidence involving dysregulation of the innate immune system, including macrophages, eosinophils, natural killer cells and mast cells that produce prostaglandins, several proinflammatory cytokines and growth factors in the development and progression of endometriosis exists [49]. Estrogen also stimulates local and systemic inflammation in women with endometriosis [50]. 


\section{Mechanisms by which endometriosis causes pain \& pain sensitization}

Women with endometriosis may present with various pain symptoms, including dysmenorrhea, chronic NMPP, dyspareunia, dyschezia and dysuria [1]. However, severe and progressive dysmenorrhea is the most characteristic pain symptom of endometriosis. The underlying mechanisms of endometriosis pain symptoms are complex and seem to include peripheral (nociceptive, inflammatory and neuropathic pain) and central (sensitization, hyperalgesia) processes [51].

Increased prostaglandin production by cyclooxygenase- 2 in the uterus or endometriotic lesions during bleeding seems to play a pivotal role in pain associated with endometriosis, particularly dysmenorrhea. Cyclooxygenase-2 is an inducible enzyme, and its production is induced by a number of inflammatory, mitogenic and physical stimuli. The proinflammatory cytokines TNF- $\alpha$ and IL- 1 stimulate the release of $\mathrm{PGE}_{2}$ and prostaglandin $\mathrm{F}_{2 \alpha}$ $\left(\mathrm{PGF}_{2 \alpha}\right)$ in endometrial cells, and $\mathrm{PGE}_{2}$ and $\mathrm{PGF}_{2 \alpha}$ are elevated in endometriotic implants [52]. Both $\mathrm{PGF}_{2 \alpha}$ and $\mathrm{PGE}_{2}$ stimulate myometrial contractions during menstruation, and $\mathrm{PGE}_{2}$ induces pain directly [53]. Thus, prostaglandin-increased uterine contractility during menstruation, often perceived as cramping, seems to represent the key mechanism of dysmenorrhea. Consistent with this mechanism, NSAIDs are often used as a first-line therapy for endometriosis-associated dysmenorrhea [1]. Some researchers proposed that the eutopic endometrium in women with endometriosis compared with women without endometriosis is infiltrated by nerve fibers, and the density of nerve fibers within the lesions may be associated with menstrual pain [54,55]. Subsequent studies have found that the nerve fibers are also increased in the eutopic endometrium in women with adenomyosis and uterine fibroids, conditions that are also associated with dysmenorrhea [56,57].

Several investigators have hypothesized that endometriosis-associated pain can be attributed to the development of new blood vessels and neurons within the endometriotic lesions (neuroangiogenesis) or the degree of tissue damage caused by endometriotic lesions and local and systemic inflammation [58-60]. In fact, in women with endometriosis, several inflammatory mediators, including proinflammatory cytokines (e.g., IL-1 $\beta$, IL-6, TNF- $\alpha$ ), prostaglandins and NGF, are elevated in peritoneal fluid or endometriotic lesions [49]. These mediators may activate nociceptors on the afferent neurons by stimulating sensory nerve fibers within the lesions, leading to the sensitization of sensory neurons and triggering pain signal cascade [60]. More recently, the ATP-gated purinergic receptor P2X ligand-gated ion channel 3 (P2X3), which is crucially involved in peripheral nociceptive processes of somatic and visceral pain, was implicated to be involved in endometriosis-associated pain via the extracellular-regulated protein kinases signaling pathway [61]. This preliminary study also suggested that increased P2X3 expression in endometriotic lesions is correlated with endometriosis pain intensity. This study also showed that IL- $1 \beta$ induces endometrial stromal cells to rapidly release ATP. ATP acts as a transmitter of signals in the synapse, has a broad range of activities in inflammatory pathways and has been implicated in chronic inflammatory diseases [62]. ATP is activated by inflammatory mediators such as IL-1 $\beta$ and released in various tissues during inflammation. IL-1 $\beta$ released from endometriotic lesions may directly activate P2X3 on sensory nerve fibers in endometriotic lesions and contribute to pain. Endometriosis is also thought to induce neuropathic pain. This type of pain is produced by damage or dysfunction of the peripheral nervous system and CNS. Although the exact contribution of neuropathic pain to the overall endometriosis-associated pain symptoms is still unknown, exploratory studies suggest that clinical features of neuropathic pain are present in more than $50 \%$ of women with chronic pelvic pain [63]. These peripheral mechanisms may play a key role in NMPP, dyspareunia and dyschezia. However, no correlation exists between the amount of endometriosis seen at laparoscopy and the severity of pain symptoms [64,65], an observation that further demonstrates the complexity of endometriosis-associated pain and the involvement of other mechanisms, including central sensitization.

Peripheral and central sensitization are considered key components of chronic pain [66], regardless of cause, which is associated with alterations in the structure and function of the CNS [67]. These mechanisms were characterized in animal models of endometriosis and in women with endometriosis. In the rat model of endometriosis, the presence of endometriotic lesions was associated with vaginal hyperalgesia [68]. A decrease in gray matter density and volume in the thalamus, cingulate cortex, insular cortex, prefrontal cortex and periaqueductal gray have been consistently found in people with chronic pain conditions [69,70] and have been corroborated in women with endometriosis [71,72]. Women with endometriosis-associated chronic pelvic pain exhibit nonpelvic hyperalgesia and decreased gray matter volume in key neural pain-processing regions of the CNS [71] and increased levels of insula excitatory neurotransmitter concentrations [72]. A diagnostic delay may contribute to the development of peripheral and central sensitization in women with endometriosis. 


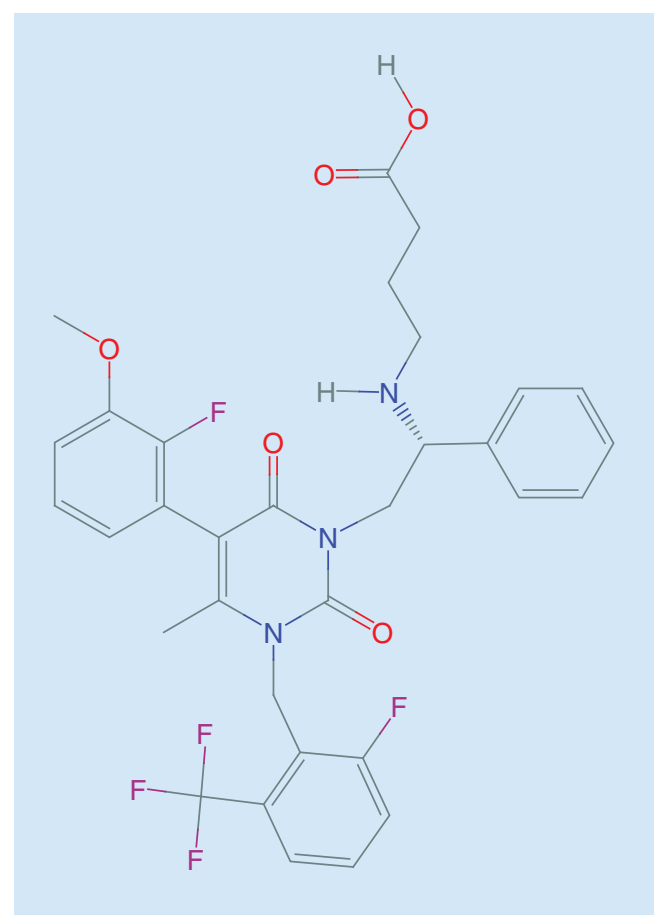

Figure 2. Elagolix.

In summary, endometriosis is a chronic inflammatory condition that is associated with often severe pelvic pain, with estrogen playing a key role in this condition.

\section{Elagolix \& other oral GnRH antagonists}

The cloning of the human GnRH receptor (hGnRH-R) as well as the subsequent characterization of its binding pocket, was a starting point for drug discovery of small molecules that bind to the human receptor. The stable expression of hGnRH-R allowed for high-throughput screening for nonpeptide, orally active GnRH antagonists that was subsequently initiated by several pharmaceutical companies [73]. Using this technology, a focused drug discovery program of oral $\mathrm{GnRH}$ antagonists was also initiated by Neurocrine Biosciences, California, that led to discovery of several lead compounds, including novel uracils [74,75]. Elagolix (Figure 2) was selected for further development based on its high binding affinity to hGnRH-R, reduced interaction with liver P450 enzymes (CYP3A4 and CYP2C19) and high efficacy in suppressing luteinizing hormone (LH) in castrated male cynomolgus macaques [76]. Based on toxicology studies in pregnant rats and rabbits, elagolix may increase the risk of early pregnancy loss. No fetal malformations were observed in embryofetal development studies in rats and rabbits [21].

\section{Other oral GnRH antagonists under development for endometriosis}

Two other oral GnRH antagonists, relugolix (TAK-385; Myovant Sciences, Takeda and ASKA Pharmaceutical) [77] and linzagolix (OBE-2109, KLH-2109; ObsEva, Kissei Pharmaceutical Co.) reached an advanced stage of clinical development for the treatment of pain associated with endometriosis and heavy menstrual bleeding associated with uterine fibroids. Both compounds are currently in Phase III clinical trials for endometriosis indication. Relugolix is being developed for endometriosis as QD treatment $(40 \mathrm{mg})$ in combination with E2 $1.0 \mathrm{mg} / \mathrm{NETA}$ $0.5 \mathrm{mg}$ add-back therapy (ClinicalTrials.gov, NCT03204318, NCT03204331 and NCT02778919). Relugolix was recently approved in Japan as a treatment for symptoms associated with uterine fibroids (ClinicalTrials.gov, NCT02655237) [78], and is also being developed for the treatment of prostate cancer (ClinicalTrials.gov, NCT03085095) [79]. Only the results of a Phase I study with relugolix alone and in combination with estradiol/norethindrone acetate add-back therapy in healthy premenopausal women have been published to date [80]. ObsEva recently announced the initiation of a development program with linzagolix that includes two Phase III studies of identical design investigating a $75-\mathrm{mg}$ single dose of linzagolix without E2 $1.0 \mathrm{mg} / \mathrm{NETA} 0.5 \mathrm{mg}$ addback therapy and a 200-mg single dose of linzagolix with add-back therapy (EDELWEISS 2 [US] and EDELWEISS 3 [Europe]) [81]. 
Phase I studies with elagolix

Several drug interaction studies have been conducted with elagolix [21]. Elagolix is a weak to moderate inducer of CYP3A and may decrease plasma concentrations of drugs that are substrates for this enzyme such as the benzodiazepine midazolam [21]. It is recommended to increase the dose of midazolam and individualize therapy based on patient's response. Elagolix may also decrease the plasma concentration of rosuvastatin, and an increased dose of rosuvastatin should be considered when coadministered with elagolix.

CY3A has been implicated in the metabolism of COCs. Therefore, drug interaction studies were also conducted for elagolix $150 \mathrm{mg}$ QD with norethindrone $0.35 \mathrm{mg}$ QD and the triphasic COC containing ethinyl estradiol 35 $\mu \mathrm{g}$ and norgestimate $0.18 / 0.215 / 025 \mathrm{mg}$ QD (a prodrug of norgestrel). No clinically significant changes in plasma concentrations of norethindrone, norelgestromin (metabolite of norgestimate) and norgestrel were observed [21]. Based on these studies, elagolix is not expected to affect the contraceptive efficacy of progestin-only contraceptives and COCs. These results are consistent with a limited role of CYP3A in the metabolism of COC components [82].

Elagolix is also an inhibitor of efflux transporter P-glycoprotein and may increase plasma concentrations of drugs that are a substrate of P-glycoprotein (e.g., digoxin). Clinical monitoring is recommended for digoxin when coadministered with elagolix.

The safety, pharmacokinetics and inhibitory effects on serum LH, follicle-stimulating hormone (FSH) and estradiol concentrations was evaluated in a placebo-controlled Phase I study in a limited number of healthy premenopausal women during a single-dose (50, 100 and $200 \mathrm{mg}$ QD) and 7-day (100 mg BID) oral administration [83]. This study showed that elagolix was well tolerated and produced a dose-dependent suppression of gonadotropins and E2, with rapid onset and rapid reversal of effects after discontinuation.

The pharmacokinetics, safety profile and hormone-suppressive effects of elagolix were further evaluated in a larger Phase I study in healthy premenopausal women during 21 days of continuous administration of increasing elagolix doses up to $400 \mathrm{mg}$ BID [84]. The results of this study confirmed its rapid absorption, reaching maximum concentrations at $1.0-1.5 \mathrm{~h}$ with a half-life of $4-6 \mathrm{~h}$ and a dose-dependent suppression of LH, FSH and E2 within hours of elagolix administration on day 1 of treatment. Continuous dosing revealed a dose-dependent suppression of gonadotropins with preferential effect on LH suppression. The E2 suppression reached a maximum using elagolix at a dose of $200 \mathrm{mg}$ BID. At elagolix doses $\geq 100 \mathrm{mg}$ BID, anovulatory progesterone concentrations were observed (Figure 3). The effects of elagolix on hormone suppression were readily reversible after stopping therapy. Elagolix demonstrated an acceptable safety profile in this study. The adverse event of hot flush was reported more frequently at higher elagolix doses; however, these events were mild in severity. The results of this study established a rationale for dose selection for Phase II and III studies in women with endometriosis and uterine fibroids by defining the doses that provide either partial or near-full E2 suppression.

The population pharmacokinetics was subsequently evaluated in a robust model that included large datasets from studies in women without and women with endometriosis. This study showed that elagolix pharmacokinetics was not affected by patient demographics and was similar between women without and women with endometriosis [85].

\section{Effects of elagolix on ovulation \& risk of pregnancies}

The effects of various elagolix doses were subsequently evaluated in a larger 3-menstrual cycle study in healthy women. This study showed that treatment with elagolix $150 \mathrm{mg}$ QD and $200 \mathrm{mg}$ BID resulted in ovulation rates of approximately 50 and 32\%, respectively [21]. These results indicate that elagolix is not contraceptive. Although women were instructed to use dual nonhormonal contraception (i.e., condom or diaphragm used with spermicide), pregnancies were reported in clinical trials with elagolix [21]. The prescribing information for elagolix (Orilissa ${ }^{\circledR}$ ) advises to use effective nonhormonal contraception during treatment with elagolix and for 1 week after its discontinuation. Based on the mechanism of action, estrogen-containing contraceptives are expected to reduce the efficacy of elagolix. The effect of progestin-only contraceptives on the efficacy of elagolix has not yet been tested in a clinical trial [21], however, based on the mechanism of action, it is unlikely to be detrimental and may provide contraception when needed. Similarly, a progestin-containing intrauterine system might also provide contraception. The addition of a progestin may even provide added efficacy.

\section{Phase II studies in women with endometriosis}

Four Phase II studies conducted by Neurocrine Biosciences have been published and are reviewed below. Two initial exploratory Phase II studies (data on file) have been neither published nor posted on ClinicalTrials.gov. The overall objective of the Phase II studies was to evaluate the safety and efficacy of elagolix at low doses (ranging from 50 


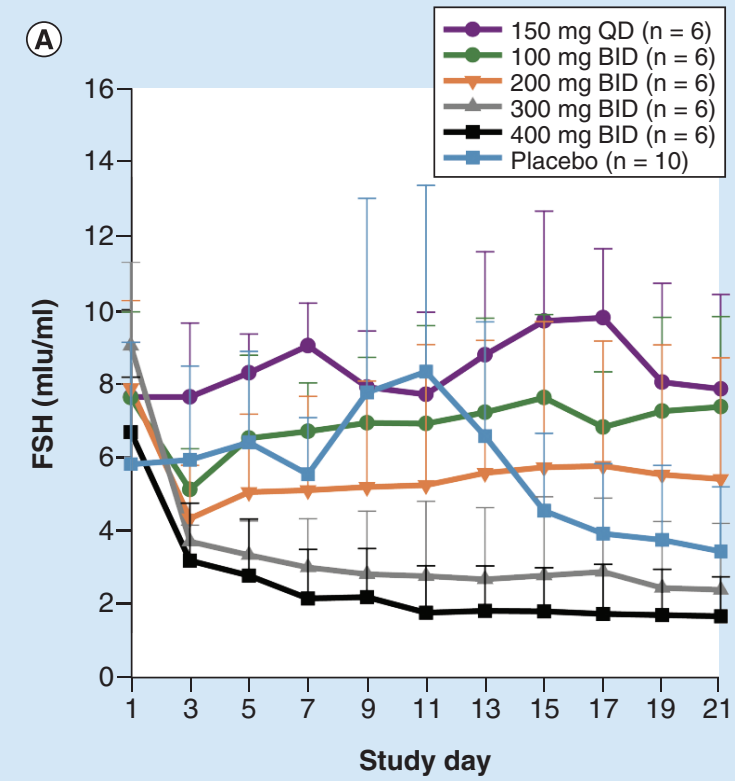

(C)

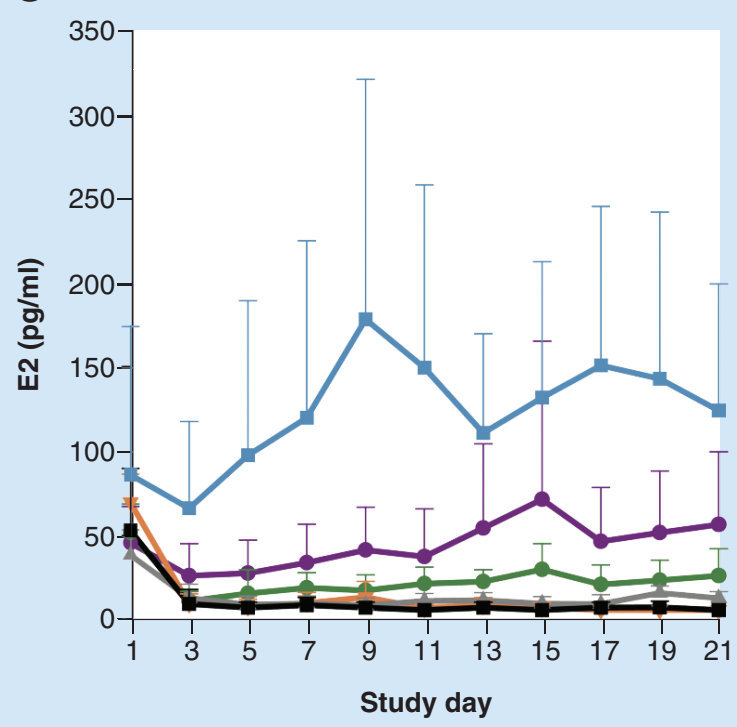

(B)

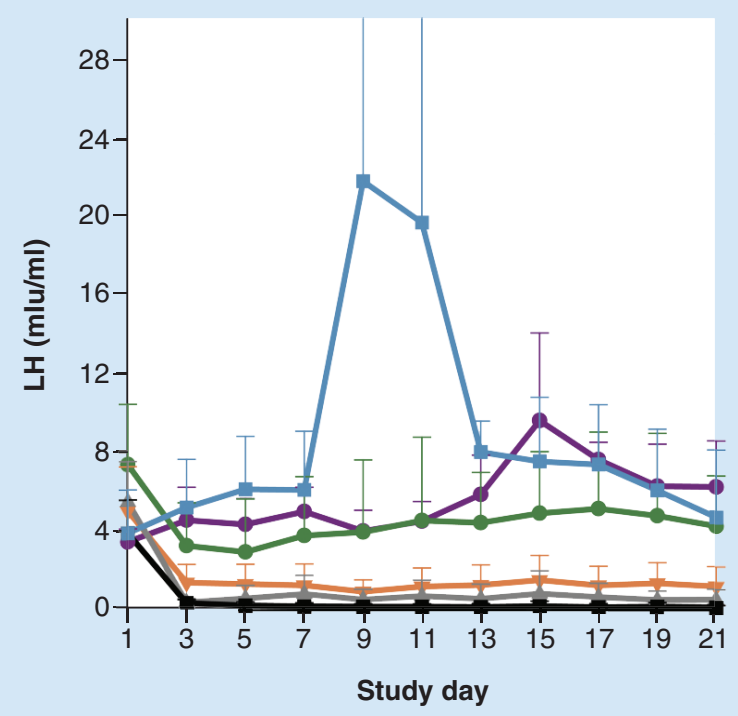

(D)

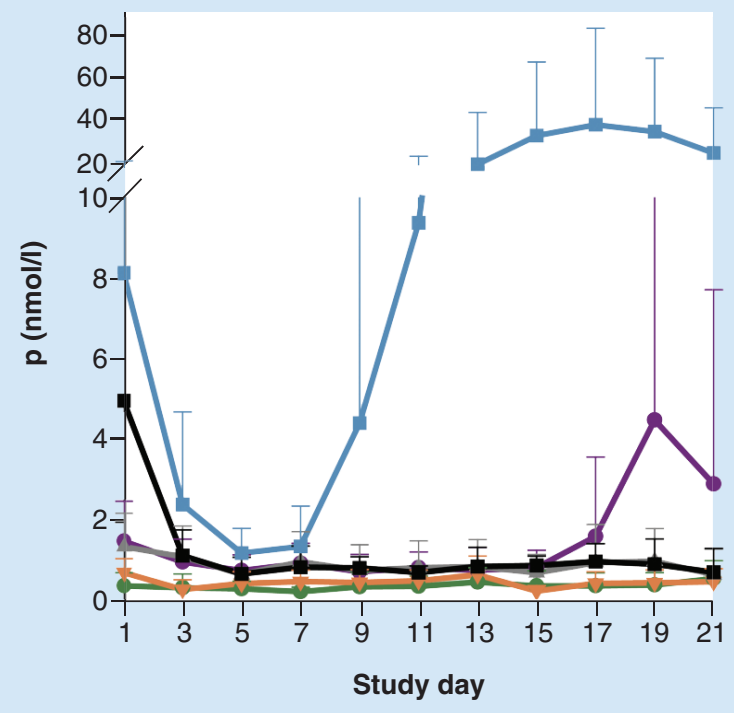

Figure 3. Dose-dependent suppression of gonadotropins (LH, FSH), E2, and progesterone in healthy premenopausal women.

Concentrations (means + SD) of FSH (A), LH (B), E2 (C) and P (D) during 21 days of dosing with placebo or elagolix. For the placebo group, the error bars for some time points have been truncated.

BID: Twice daily; E2: Estradiol; FSH: Follicle-stimulating hormone; LH: Luteinizing hormone; P: Progesterone; QD: Once daily; SD: Standard deviation.

Reprinted with permission from [84].

to $250 \mathrm{mg}$ QD and $75 \mathrm{mg} \mathrm{BID)} \mathrm{that} \mathrm{produce} \mathrm{partial} \mathrm{estradiol} \mathrm{suppression.} \mathrm{Although} \mathrm{all} \mathrm{of} \mathrm{these} \mathrm{studies} \mathrm{included}$ elagolix $150 \mathrm{mg}$ QD doses, limitations of cross-study comparisons due to differences in study population, study design and pain assessment methods exist. All of these studies were conducted in women with laparoscopically confirmed endometriosis and moderate to severe pain.

\section{Safety Phase II randomized study with elagolix versus subcutaneous DMPA (NBI-56418-0603; NCT00437658)}

The primary objective of this safety study was to evaluate the effects of elagolix (150 mg QD and $75 \mathrm{mg}$ BID) versus subcutaneous DMPA (DMPA-SC) on bone mineral density (BMD; primary end point) after treatment 
for 6 months with a subsequent 6-month follow-up period in women with endometriosis-associated pain [86]. DMPA-SC was selected as an active comparator because of its well-established efficacy in reducing endometriosis pain, which is similar to that of LA [87,88]. The efficacy assessments, which were secondary end points, included: improvements in dysmenorrhea, NMPP and dyspareunia using the Composite Pelvic Signs and Symptoms Score (CPSSS; based on 4-point Biberoglu and Behrman [B\&B] scale with monthy recall period); and improvement in pain assessment with visual analog scale (VAS; 0-100) used as an electronic daily diary. All treatments induced minimal mean changes from baseline in spine BMD at week 24 (elagolix $150 \mathrm{mg}:-0.11 \%$, elagolix $75 \mathrm{mg}:-1.29 \%$ and DMPA-SC: 0.99\%). Elagolix was associated with improvements in endometriosis-associated pain, assessed with CPSSS and VAS, including statistical noninferiority of elagolix $150 \mathrm{mg}$ QD to DMPA-SC in dysmenorrhea and NMPP pain components of the CPSSS. There were also improvements in quality of life as measured by the Endometriosis Health Profile-5 (EHP-5). There were some differences in tolerability between elagolix and DMPA-SC (e.g., a decrease in uterine bleeding with elagolix vs an increase in breakthrough bleeding and spotting in the DMPA-SC group). This study showed that elagolix $150 \mathrm{mg}$ QD treatment for 6 months was effective in improving endometriosis-associated pain with minimal effects on BMD.

\section{Safety \& efficacy Phase II study with elagolix versus placebo (NBI-56418-0702; NCT00619866)}

The primary objective of this study was to evaluate the safety and efficacy of elagolix (150 mg and $250 \mathrm{mg}$ QD) versus placebo for 12 weeks [89]. Patients receiving placebo were rerandomized to elagolix and patients receiving elagolix continued their dosing assignment for 12 additional weeks. The primary efficacy measure was change from baseline in the monthly mean numerical rating scale (NRS) for pelvic pain at week 12 . This study showed a nonsignificant trend toward greater monthly mean NRS reductions with elagolix versus placebo. However, monthly mean dysmenorrhea and NMPP pelvic pain scores measured with daily modified B\&B scale were reduced with elagolix, with statistically significant differences versus placebo for dysmenorrhea and dyspareunia during the first 12 weeks $(\mathrm{p}<0.05)$ and minimal changes in BMD.

\section{Safety \& efficacy Phase II study with elagolix versus intramuscular LA (NBI-56418-0703; NCT00797225)}

In this study, women with endometriosis were randomized to elagolix 150 or $250 \mathrm{QD}$, placebo or LA $3.75 \mathrm{mg}$ monthly for 12 weeks [90]. Placebo and LA study participants were rerandomized to elagolix for an additional 12 weeks of treatment. This study was powered to compare elagolix with placebo, not to compare elagolix with LA. There was no prespecified primary efficacy end point for this exploratory Phase II study. Efficacy measures included daily assessment of pelvic pain using the NRS and daily assessment of dysmenorrhea and NMPP using a modified $\mathrm{B} \& \mathrm{~B}$ scale adapted for daily use. Significantly greater reductions in monthly mean pelvic pain compared with placebo $(\mathrm{p}<0.05)$ were observed at both elagolix doses at week 4; elagolix $250 \mathrm{mg}$ at week 8; and LA at weeks 4, 8 and 12; there was no statistically significant benefit with elagolix at week 12. During treatment weeks 4-12, both elagolix doses partially suppressed median E2 concentrations (150 mg: 36.4-39.6 pg/ml; $250 \mathrm{mg}$ : 22.0$26.2 \mathrm{pg} / \mathrm{ml}$ ) compared with placebo, whereas LA fully suppressed median E2 concentration to 3.6-6.4 pg/ml; E2 concentrations correspond to percentage reductions in spinal BMD from baseline at week 12 (elagolix $150 \mathrm{mg}$ QD: - 1.05; elagolix $250 \mathrm{mg}$ QD: -0.80; LA: -1.63; placebo: 0.11).

\section{Safety \& efficacy Phase II study with elagolix versus placebo (NBI-56418-0901; NCT00973973)}

This was a randomized study in women with laparoscopically confirmed endometriosis and moderate to severe NMPP and dysmenorrhea that consisted of an 8-week, double-blind period with elagolix $150 \mathrm{mg}$ QD and placebo followed by a 16-week open-label period with elagolix $150 \mathrm{mg}$ QD [91]. The primary outcomes of the study were changes in dysmenorrhea and NMPP versus placebo at week 8 assessed using an electronic, daily, 4-point pain-impact diary. The items of this scale, which was based on the modification of the patient-reported B\&B questionnaire, were developed across three stages of qualitative research, and the psychometric properties of the scale were validated in a Phase II clinical trial [92] according to the FDA guidelines on patient-reported outcome development [93]. This was the first study that used this scale and showed an increased ability (i.e., greater sensitivity) to detect change in both dysmenorrhea and NMPP compared with the 4-point scale used in previous elagolix Phase II studies. Compared with other pain scales, such as NRS and VAS, which assess the intensity of pain, this scale includes the impact of pain on everyday functioning. This scale was subsequently used in elagolix Phase III studies. Other clinical outcomes included changes in dyspareunia measured daily, monthly assessment of pain symptoms 
using CPSSS and quality-of-life measures using the EHP-5. The occurrence and intensity of uterine bleeding were recorded using an electronic daily 4-point bleeding diary.

During the double-blind period of this study at week 8, treatment with elagolix $150 \mathrm{mg}$ QD was associated with statistically significant reductions in dysmenorrhea and NMPP versus placebo. There was also a statistically significant reduction in dyspareunia and cumulative pain scores assessed with CPSSS. Additionally, elagolix treatment was associated with a significant decrease in analgesic use and improvements in quality-of-life measures. These effects were maintained during the open-label period of this study. The treatment with elagolix was generally well tolerated. Over the 24 weeks of treatment, the most frequently reported adverse events were headache, hot flush and nausea (all 9.9\% of women). The amenorrhea rate of women who received elagolix during the 8-week placebo-controlled treatment period was $25.8 \%$; the majority of remaining women had regular but prolonged cycles, with a low rate of breakthrough bleeding and spotting.

\section{Phase III studies in women with endometriosis}

The Phase III program consisted of two large, multicenter, double-blind, randomized, placebo-controlled, 6-month trials (Elaris Endometriosis I and II [Elaris EM-I and Elaris EM-II]) [94] with two elagolix doses (150 mg QD and $200 \mathrm{mg} \mathrm{BID}$ ) and two double-blind, randomized, 6-month extension studies in women with surgically diagnosed endometriosis and moderate or severe endometriosis-associated pain. The extension studies (Elaris EM-III and Elaris EM-IV) enrolled women who completed one of the two preceding placebo-controlled Elaris EM-I and Elaris EM-II Phase III studies and were designed to evaluate the long-term outcomes during continuous treatment for 12 months [95].

\section{Placebo-controlled Phase III trials (Elaris EM-I \& Elaris EM-II)}

Both placebo-controlled replicate Phase III studies (Elaris EM-I [NCT01620528] and Elaris EM-II [NCT01931670]) were conducted in women with surgically diagnosed endometriosis and moderate to severe endometriosis-associated pain. These studies had a similar design but included a different population; Elaris EM-I $(\mathrm{n}=872)$ was conducted in the USA, whereas Elaris EM-II $(\mathrm{n}=817)$ was a global study. Each trial was divided into four periods: a washout of hormonal therapies (if applicable); a screening period including two menstrual cycles, during which women switched from the use of usual analgesic agents to receive allowed rescue medication of an NSAID ( $500 \mathrm{mg}$ of naproxen), an opioid according to country (e.g., $5 \mathrm{mg}$ of hydrocodone plus $325 \mathrm{mg}$ of acetaminophen), or both; a 6-month treatment period; and a follow-up period of up to 12 months, unless the women were enrolled in the corresponding 6-month extension study. Women were instructed to use dual nonhormonal contraception during these studies. Most women (74.9 and 77.4\% in Elaris EM-I and EM-II, respectively) completed these studies. The primary reasons for discontinuation were withdrawal of consent (6.1-9.6\%), adverse events (4.4-10.0\%) and lost to follow-up (3.1-6.7\%) [94]. The median age of women in the trials was 32 years; 88\% were white, 9\% were black or African American and 3\% were other races. In EM-I and EM-II, 59 and 60\%, respectively, of women used an opioid rescue analgesic (hydrocodone/acetaminophen or codeine/acetaminophen) for pain at baseline.

The two primary efficacy end points were the proportion of women who showed clinically meaningful responses (pain reduction and stable/decreased rescue analgesic use) with respect to dysmenorrhea and NMPP pain at month 3 of treatment assessed using the validated, electronic, daily 4-point pain-impact diary [92]. The clinically meaningful response thresholds with respect to dysmenorrhea and NMPP were calculated before unblinding using a receiver operating characteristics analysis with Patient Global Impression of Change (PGIC) responses ('much improved', 'very much improved') as an anchor. This method is commonly used in pain studies [96]; however, it was used in these studies for the first time in an endometriosis population. The response threshold calculated with this method is generally viewed as clinically meaningful [96]. Key secondary efficacy end points included: mean changes from baseline to month 3 in endometriosis-associated pain, as assessed with the 11-point NRS; significant reduction in baseline in dysmenorrhea at month 6; significant reduction in baseline in NMPP at month 6; use of rescue analgesics (NSAIDs, opioids, or both) at months 3 and 6; significant change from baseline in dyspareunia at month 3 ; and use of rescue opioids at month 3. These end points were tested in a hierarchical order. Additional efficacy end points included improvements in PGIC and the 30-item Endometriosis Health Profile (EHP-30) questionnaire. Safety evaluations included endometrial assessment, laboratory measures and changes in BMD.

In these two trials, both elagolix doses (150 mg QD or $200 \mathrm{mg}$ BID) resulted in a significantly greater proportion of women with a clinically meaningful response with respect to dysmenorrhea and NMPP compared with placebo 


\section{Placebo Elagolix, $150 \mathrm{mg}$ once daily Elagolix, $200 \mathrm{mg}$ once daily}

\section{(A) Elaris EM-I}

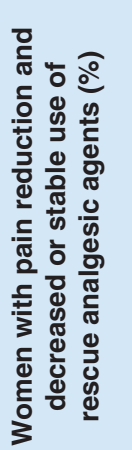

Dysmenorrhea

Nonmenstrual pelvic pain
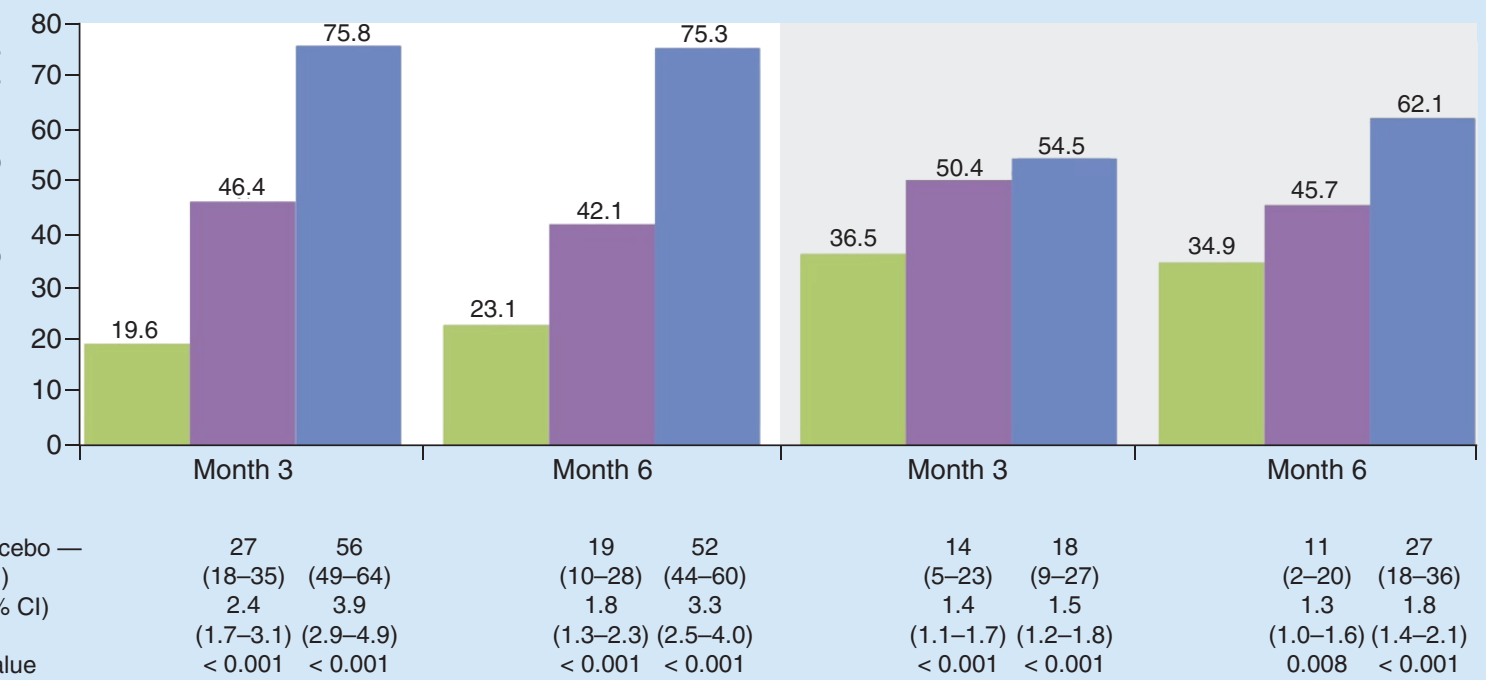
Difference from placebo -
$\%(97.5 \% \mathrm{Cl})$
Risk ratio $(97.5 \% \mathrm{Cl})$
$<0.001<0.001$

$<0.001<0.001$

$\begin{array}{cc}14 & 18 \\ (5-23) & (9-27) \\ 1.4 & 1.5 \\ (1.1-1.7) & (1.2-1.8) \\ <0.001 & <0.001\end{array}$

$(2-20) \quad(18-36)$

$1.3 \quad 1.8$

$(1.0-1.6)(1.4-2.1)$

$0.008<0.001$

\section{(B) Elaris EM-II}

\section{Dysmenorrhea}

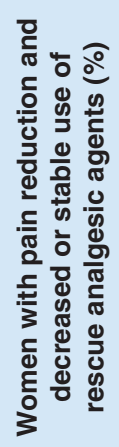

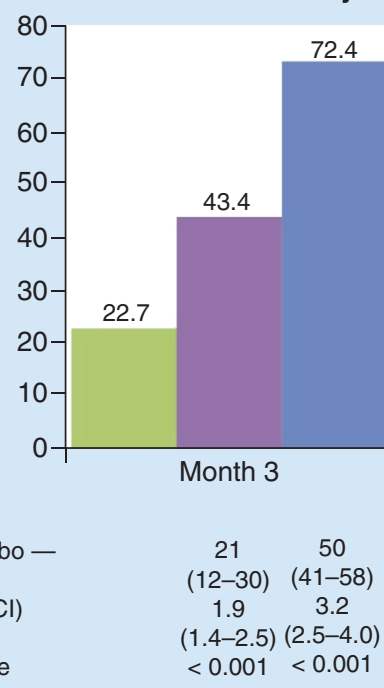

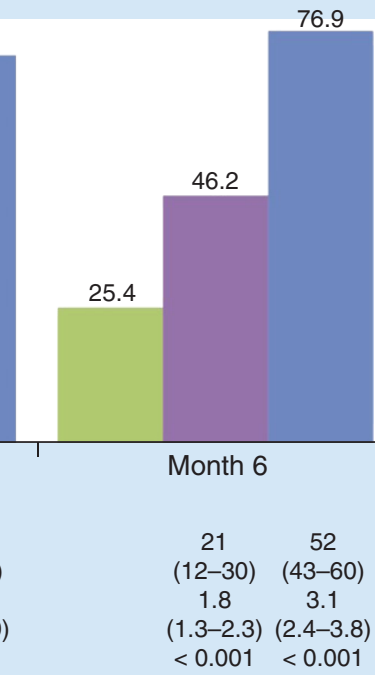

\section{Nonmenstrual pelvic pain}

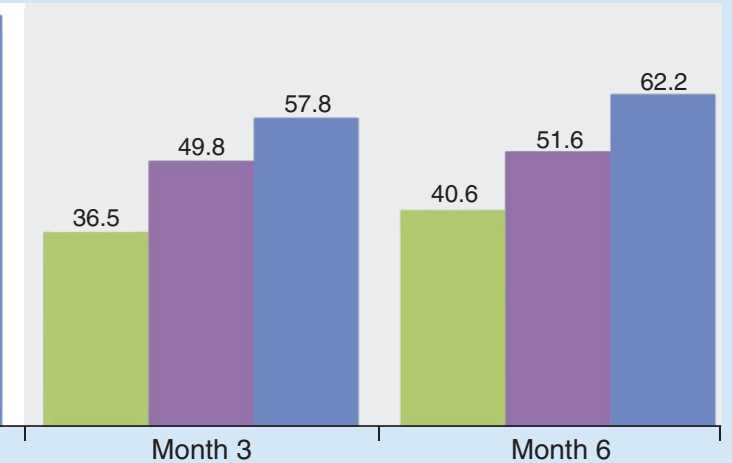

\begin{abstract}
Two-sided $p$-value
ce from placebo -

$$
\%(97.5 \% \mathrm{Cl})
$$

$\%(97.5 \% \mathrm{Cl})$
Risk ratio $(97.5 \% \mathrm{Cl})$

p-value
\end{abstract}

Figure 4. Reduction in dysmenorrhea and nonmenstrual pelvic pain during treatment with elagolix in women with

endometriosis-associated pain (Elaris EM-I and EM-II studies). Shown are the percentages of women in whom the two primary end points (clinically meaningful reduction in dysmenorrhea or in NMPP, as measured by the decreased or stable use of rescue analgesic agents) were reported at 3 and 6 months in Elaris EM-I (A) and Elaris EM-II (B). In Elaris EM-I, 3-month data are provided for 373 women who received placebo, 248 who received the lower elagolix dose (150 mg QD) and 244 who received the higher elagolix dose (200 mg BID); the corresponding 6-month data are provided for 372, 247 and 243 women. In Elaris EM-II, 3-month data are provided for 353 women who received placebo, 221 who received the lower elagolix dose and 225 who received the higher elagolix dose; the corresponding 6-month data are provided for 355, 221 and 225 women.

BID: Twice daily; EM: Endometriosis; NMPP: Nonmenstrual pelvic pain; QD: Once daily.

Reprinted with permission from [94] (c) Massachusetts Medical Society (2017). 


\section{(A) Elaris EM-I}
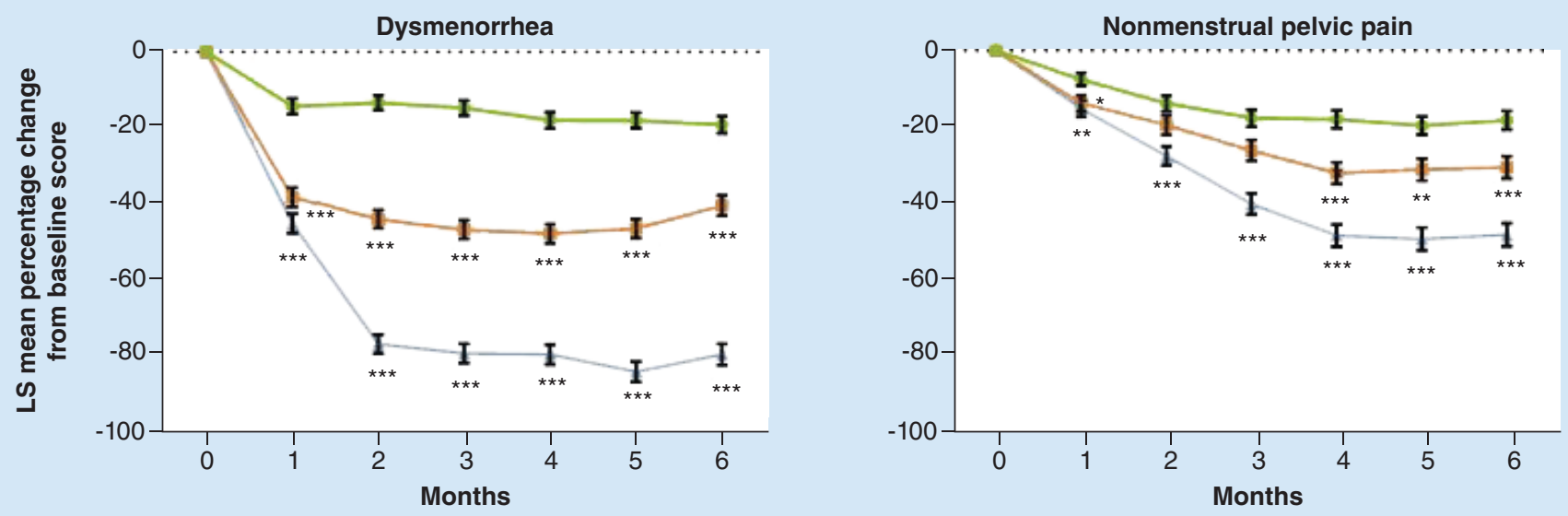

(B) Elaris EM-II
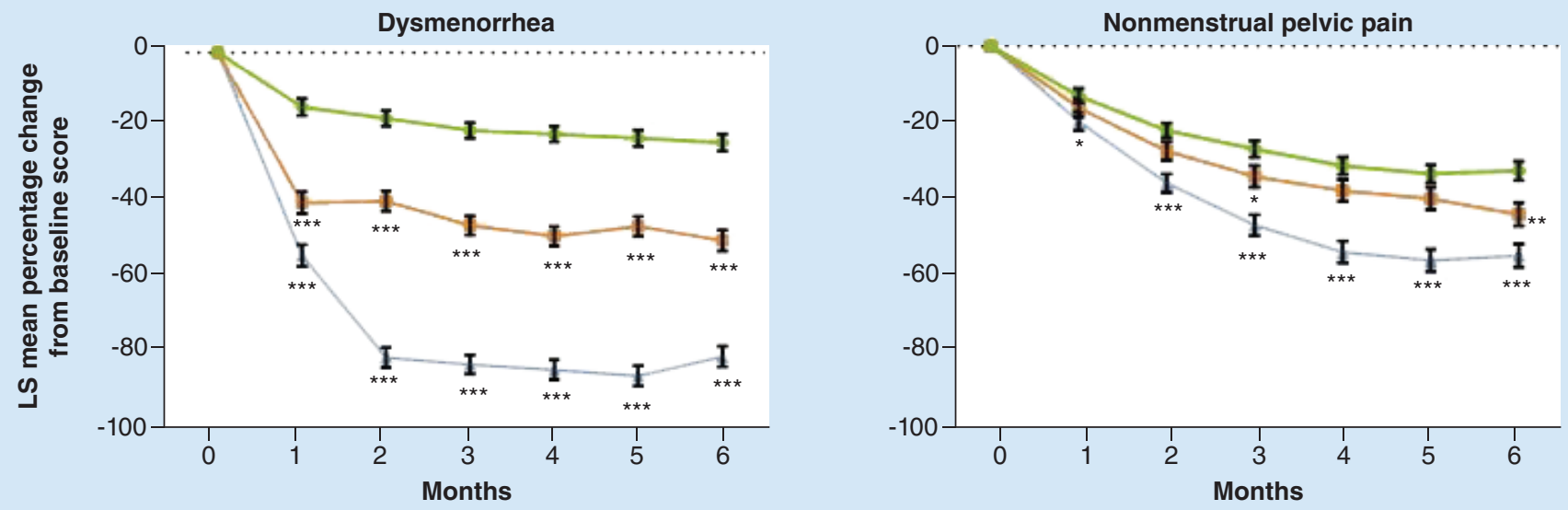

Figure 5. Mean percentage change from baseline in dysmenorrhea and nonmenstrual pelvic pain scores during treatment with elagolix in women with endometriosis-associated pain (Elaris EM-I and EM-II studies). Statistical significance compared with placebo for the mean percentage change from baseline score in Elaris EM-I (A) and Elaris EM-II (B) was based on a mixed-effects model with repeated measures with treatment as the main effect, visit as the repeated measure, baseline value as a covariate and an interaction between treatment and visit, using observed data, indicated by: ${ }^{*} p<0.05 ;{ }^{*} p<0.01 ; * * * p \leq 0.001$. Error bars represent standard error.

EM: Endometriosis; LS: Least squares.

Reprinted with permission from [94] () Massachusetts Medical Society (2017).

at month 3 (primary efficacy end points; Figure 4). These effects were dose dependent and sustained at month 6 of treatment. Both elagolix doses resulted in a significant reduction from baseline to month 3 in NRS and significant reductions from baseline to month 6 in dysmenorrhea and NMPP compared with placebo (Figure 5). Only elagolix $200 \mathrm{mg}$ BID significantly reduced dyspareunia and the use of rescue analgesic agents (as determined by the mean pill counts of NSAIDs, opioids or both) at 3 and 6 months compared with women who received placebo.

Consistent with the improvement in pain, significantly more women taking either dose of elagolix reported 'much' or 'very much' improvement on the PGIC scale at 6 months than did those taking placebo. Elagolix treatment resulted in a better quality of life than did placebo on the basis of the mean change from baseline to 3 and 6 months on EHP-30 dimensions. At these time points, significant changes were observed at elagolix $150 \mathrm{mg}$ QD in three of the six dimensions in Elaris EM-I and in four of the six dimensions in Elaris EM-II and at elagolix $200 \mathrm{mg}$ BID in all dimensions in both studies. 
The most frequently reported adverse events in each trial were hot flushes, headache and nausea, with the rate of hot flushes being significantly higher with each dose of elagolix compared with placebo. However, the severity of elagolix-associated hot flushes was mild or moderate in most women, and the discontinuation rate due to hot flushes was low ( $<1$ and 3\% with elagolix $150 \mathrm{mg}$ QD and $200 \mathrm{mg}$ BID, respectively). There was a significant dose-dependent decrease in spine, total hip and femoral neck BMD at month 6 of treatment in both elagolix groups compared with placebo (with the exception of femoral neck BMD at elagolix $150 \mathrm{mg}$ QD). The changes in lumbar spine BMD at month 6 ranged between -0.32 to $-0.72 \%$ and -2.61 to $-2.49 \%$ at elagolix $150 \mathrm{mg}$ QD and $200 \mathrm{mg}$ BID, respectively. By comparison, treatment with the GnRH agonist LA reduced the lumbar spine BMD by 3.2\% at month 3 and $6.3 \%$ at month 6 of treatment alone without add-back [19]. Consistent with the hypoestrogenic effect of elagolix, there was a shift in the lipid profile (increased high-density lipoprotein cholesterol [HDL-C] and low-density lipoprotein cholesterol [LDL-C] levels), with little changes in LDL/HDL ratio. In the placebo-controlled studies (Elaris EM-I and Elaris EM-II), dose-dependent asymptomatic elevations of serum ALT to at least three-times the upper limit of the reference range occurred during treatment with elagolix (150 mg QD, 1/450, 0.2\%; $200 \mathrm{mg}$ QD 5/443, 1.1\%; placebo 1/696, 0.1\%). Similar increases were seen in the extension studies presented below. There were no cases of liver injuries attributed to elagolix treatment [21]. There were no adverse endometrial biopsy findings, and the endometrial biopsy results suggested an antiproliferative effect of both elagolix doses and endometrial atrophy at elagolix $200 \mathrm{mg}$ BID.

\section{Phase III extension studies (Elaris EM-III \& Elaris EM-IV)}

Elaris EM-III (NCT01760954) and Elaris EM-IV (NCT02143713) were extension studies of the double-blind, placebo-controlled Phase III studies (Elaris EM-I and Elaris EM-II) [95]. The objective of these studies was to evaluate the long-term outcomes after an additional 6 months of treatment (total of 12 months of continuous treatment). These studies consisted of the 6-month treatment period and a post-treatment follow-up period of up to 12 months. Women who were on active treatment used the same elagolix dose in the extension studies, whereas women who received placebo in the preceding studies were rerandomized to each elagolix dose group. Only data from women who received elagolix over the course of 12 months have been published [95]. Both studies used the same efficacy end points as the placebo-controlled studies discussed above.

Long-term elagolix treatment provided sustained reductions in dysmenorrhea, NMPP and dyspareunia, as demonstrated by clinically meaningful response to treatment and changes from baseline in pain scores, which were comparable with those observed in placebo-controlled preceding studies (Figure 6).

The safety profile of elagolix was consistent with hypoestrogenic effects, and no new safety concerns were identified in these long-term studies. The most common adverse events in either study were hot flushes, headache and nausea. The incidence of hot flushes was dose dependent, with the maximum severity of mild to moderate in most women. After 12 months of treatment, the mean percent changes from baseline in lumbar spine BMD in Elaris EM-III and Elaris EM-IV were -0.63 and $-1.1 \%$ with elagolix $150 \mathrm{mg}$ QD and -3.60 and $-3.91 \%$ with elagolix $200 \mathrm{mg}$ BID, respectively. After the cessation of treatment, a continuous recovery from BMD loss was observed. Similar to Elaris EM-I and EM-II, elagolix treatment was associated with changes in the lipid profile during the extension studies. These changes were small and included both favorable (increase in HDL-C) and unfavorable (increase in LDL-C and triglycerides) effects, and the lipid profile returned to pretreatment levels within month 1 of the post-treatment follow-up period. There were no adverse endometrial findings, and endometrial biopsy results were consistent with an antiproliferative effect of elagolix.

In summary, the use of elagolix at two doses (150 mg QD and $200 \mathrm{mg}$ BID) resulted in significant reductions in two of the main pain symptoms of endometriosis, dysmenorrhea and NMPP, after both 3 and 6 months of treatment. The higher elagolix dose was effective in improving dyspareunia and reducing opioid use. Consistent with the mechanism of action, elagolix treatment resulted in hypoestrogenic effects, including hot flushes and changes in BMD and lipid levels. Although these studies did not have prespecified statistical testing to compare the two elagolix doses, women in the higher-dose group (200 mg BID) had a greater reduction in pain and more severe hypoestrogenic adverse effects than those in the lower-dose group (150 mg QD), which suggests the possibility of an individualized treatment approach depending on symptoms and hypoestrogenic effects.

\section{Conclusion}

The approval of elagolix in the USA and Canada offers a new medical treatment option for the management of moderate and severe pain associated with endometriosis. The recommended treatment duration in women with 


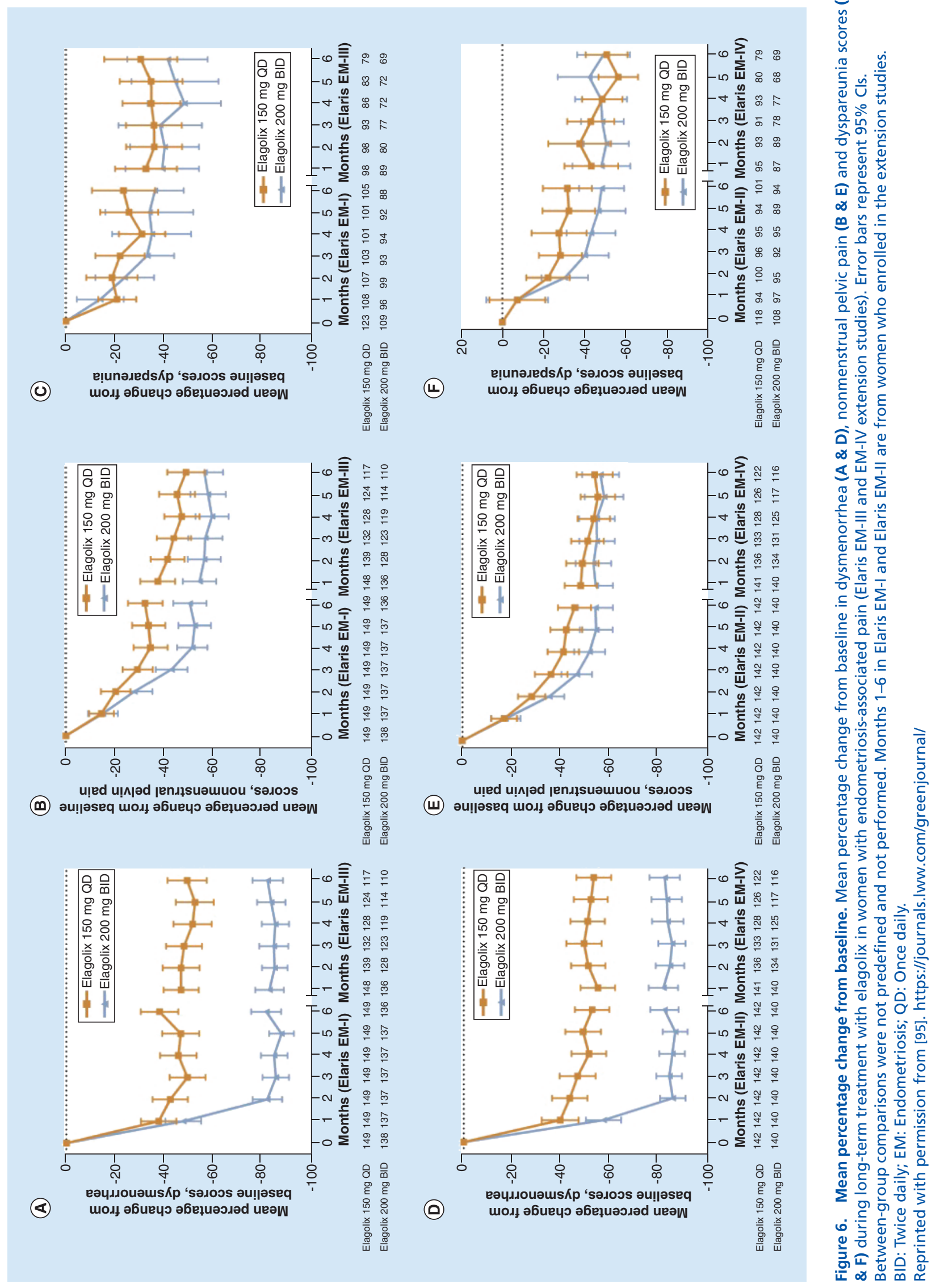


normal liver function or mild hepatic impairment is up to 24 months for $150 \mathrm{mg}$ QD and up to 6 months for $200 \mathrm{mg}$ BID [21]. As an oral, short-acting competitive GnRH receptor antagonist, elagolix has a novel mechanism of action that differs from that of depot GnRH agonists. In contrast to GnRH agonists, elagolix produces dosedependent estrogen suppression from partial suppression at the lower dose (150 mg QD) to nearly full suppression at the higher dose (200 mg BID), therefore suggesting the possibility of individual tailoring of these two doses depending on the severity of symptoms to balance efficacy and hypoestrogenic side effects. In addition, an oral $\mathrm{GnRH}$ antagonist is characterized with a rapid onset and cessation of hormone suppression.

\section{Future Perspective}

Two new oral GnRH antagonists, relugolix and linzagolix, are in an advanced stage of clinical development for the management of pain associated with endometriosis. Future studies will show whether the treatment of women with endometriosis using oral GnRH antagonists could be assisted with noninvasive/minimally invasive endometriosis biomarkers that are currently under development [97,98], creating an opportunity for a precision medicine approach in endometriosis. These biomarkers have the potential to reduce the delay in the diagnosis of endometriosis, identify women with progesterone resistance, and predict treatment response [18,99]. The shortening of the diagnostic delay and an early use of targeted therapies such as elagolix may reduce the development of central sensitization and lead to the overall improvement of quality of life in women with endometriosis. Elagolix is also under investigation in Phase III studies for the treatment of heavy menstrual bleeding associated with uterine fibroids $[90,91,100,101]$. Premenopausal women treated with elagolix for leiomyoma associated heavy menstrual bleeding with and without add-back therapy have shown significant reduction in menstrual bleeding and improved quality of life $[100,101]$. Additional evaluation of the safety and efficacy of elagolix after multiple treatment courses, as well as a combination of high-dose elagolix with add-back therapy, is warranted.

\section{Financial \& competing interests disclosure}

AbbVie Inc. funded the elagolix research reviewed in this article and participated in the review and approval of this publication. HS Taylor has served as a consultant for AbbVie, Bayer, ObsEva and DotLab and is funded by the NIH. K Chwalisz is an employee of AbbVie, receiving stock or stock/options. The authors have no other relevant affiliations or financial involvement with any organization or entity with a financial interest in or financial conflict with the subject matter or materials discussed in the manuscript apart from those disclosed.

Editorial support, funded by AbbVie, was provided by MJ Theisen, of Complete Publication Solutions LLC (PA, USA).

\section{Open access}

This work is licensed under the Attribution-NonCommercial-NoDerivatives 4.0 Unported License. To view a copy of this license, visit http://creativecommons.org/licenses/by-nc-nd/4.0/

\section{References}

Papers of special note have been highlighted as: $\bullet$ of interest; $\bullet \bullet$ of considerable interest

1. Giudice LC. Clinical practice. Endometriosis. N. Engl. J. Med. 362(25), 2389-2398 (2010).

2. Bulun SE. Endometriosis. N. Engl. J. Med. 360(3), 268-279 (2009).

3. Vercellini P, Meana M, Hummelshoj L, Somigliana E, Vigano P, Fedele L. Priorities for endometriosis research: a proposed focus on deep dyspareunia. Reprod. Sci. 18(2), 114-118 (2011).

4. Gao X, Outley J, Botteman M, Spalding J, Simon JA, Pashos CL. Economic burden of endometriosis. Fertil. Steril. 86(6), 1561-1572 (2006).

5. Nnoaham KE, Hummelshoj L, Webster P et al. Impact of endometriosis on quality of life and work productivity: a multicenter study across ten countries. Fertil. Steril. 96(2), 366-373 (2011).

6. Simoens S, Dunselman G, Dirksen C et al. The burden of endometriosis: costs and quality of life of women with endometriosis and treated in referral centres. Hum. Reprod. 27(5), 1292-1299 (2012).

7. Soliman AM, Taylor HS, Bonafede M, Nelson JK, Castelli-Haley J. Incremental direct and indirect cost burden attributed to endometriosis surgeries in the United States. Fertil. Steril. 107(5), 1181.e2-1190.e2 (2017).

8. Simoens S, Hummelshoj L, Dunselman G et al. Endometriosis cost assessment (the EndoCost study): a cost-of-illness study protocol. Gynecol. Obstet. Invest. 71(3), 170-176 (2011).

9. Culley L, Law C, Hudson $\mathrm{N}$ et al. The social and psychological impact of endometriosis on women's lives: a critical narrative review. Hum. Reprod. Update 19(6), 625-639 (2013). 
10. Du H, Taylor HS. Contribution of bone marrow-derived stem cells to endometrium and endometriosis. Stem Cells 25(8), $2082-2086$ (2007).

11. Johnson NP, Hummelshoj L. World Endometriosis Society Montpellier C. Consensus on current management of endometriosis. Hum. Reprod. 28(6), 1552-1568 (2013).

12. Vercellini P, Crosignani PG, Abbiati A, Somigliana E, Vigano P, Fedele L. The effect of surgery for symptomatic endometriosis: the other side of the story. Hum. Reprod. Update 15(2), 177-188 (2009).

13. Seracchioli R, Mabrouk M, Manuzzi L et al. Post-operative use of oral contraceptive pills for prevention of anatomical relapse or symptom-recurrence after conservative surgery for endometriosis. Hum. Reprod. 24(11), 2729-2735 (2009).

14. Guo SW. Recurrence of endometriosis and its control. Hum. Reprod. Update 15(4), 441-461 (2009).

15. Practice bulletin no. 114: management of endometriosis. Obstet. Gynecol. 116(1), 223-236 (2010).

16. Dunselman GA, Vermeulen N, Becker C et al. ESHRE guideline: management of women with endometriosis. Hum. Reprod. 29(3), 400-412 (2014).

17. Jensen JT, Schlaff W, Gordon K. Use of combined hormonal contraceptives for the treatment of endometriosis-related pain: a systematic review of the evidence. Fertil. Steril. 110(1), 137.e1-152.e1 (2018).

18. Flores VA, Vanhie A, Dang T, Taylor HS. Progesterone receptor status predicts response to progestin therapy in endometriosis. J. Clin. Endocrinol. Metab. 103(12), 4561-4568 (2018).

- A recent report showing that loss of progesterone receptor makes lesions unresponsive to progestin-based treatments, such as combined oral contraceptives.

19. Hornstein MD, Surrey ES, Weisberg GW, Casino LA. Leuprolide acetate depot and hormonal add-back in endometriosis: a 12-month study. Lupron Add-Back Study Group. Obstet. Gynecol. 91(1), 16-24 (1998).

20. Barbieri RL. Hormone treatment of endometriosis: the estrogen threshold hypothesis. Am. J. Obstet. Gynecol. 166(2), 740-745 (1992).

- First hypothesis that rather than complete suppression just lowering estrogen levels would lead to regression of endometriosis with fewer menopausal side effects.

21. Abbvie Inc. Prescribing information for Orilissa ${ }^{T M}$ (elagolix) tablets, for oral use (2018). https://www.orilissa.com/

22. Millar RP, Newton CL. Current and future applications of GnRH, kisspeptin and neurokinin B analogues. Nat. Rev. Endocrinol. 9(8), 451-466 (2013).

23. Maggi R, Cariboni AM, Marelli MM et al. GnRH and GnRH receptors in the pathophysiology of the human female reproductive system. Hum. Reprod. Update 22(3), 358-381 (2016).

24. Sampson JA. Peritoneal endometriosis due to the menstrual dissemination of endometrial tissue into the peritoneal cavity. Am. J. Obstet. Gynecol. 14(4), 422-469 (1927).

25. Nunley WC Jr, Kitchin JD 3rd. Congenital atresia of the uterine cervix with pelvic endometriosis. Arch. Surg. 115(6), 757-758 (1980).

26. Olive DL, Henderson DY. Endometriosis and mullerian anomalies. Obstet. Gynecol. 69(3 Pt 1), 412-415 (1987).

27. Sanfilippo JS, Wakim NG, Schikler KN, Yussman MA. Endometriosis in association with uterine anomaly. Am. J. Obstet. Gynecol. 154(1), 39-43 (1986).

28. Sampson JA. Metastatic or embolic endometriosis, due to the menstrual dissemination of endometrial tissue into the venous circulation. Am. J. Pathol. 3(2), 93.43-110.43 (1927).

29. Sampson JA. Heterotopic or misplaced endometrial tissue. Am. J. Obstet. Gynecol. 10, 664 (1925).

30. Leyendecker G, Herbertz M, Kunz G, Mall G. Endometriosis results from the dislocation of basal endometrium. Hum. Reprod. 17(10), 2725-2736 (2002).

31. Sasson IE, Taylor HS. Stem cells and the pathogenesis of endometriosis. Ann. NY Acad. Sci. 1127, 106-115 (2008).

32. Taylor HS. Endometrial cells derived from donor stem cells in bone marrow transplant recipients. JAMA 292(1), 81-85 (2004).

-. The first description of stem cell contribution to endometrium and endometriosis.

33. Fung JN, Rogers PA, Montgomery GW. Identifying the biological basis of GWAS hits for endometriosis. Biol. Reprod. 92 (4), 87 (2015).

34. Dun EC, Taylor RN, Wieser F. Advances in the genetics of endometriosis. Genome Med. 2(10), 75 (2010).

35. Sapkota Y, Steinthorsdottir V, Morris AP et al. Meta-analysis identifies five novel loci associated with endometriosis highlighting key genes involved in hormone metabolism. Nat. Commun. 8, 15539 (2017).

36. Chettier R, Ward K, Albertsen HM. Endometriosis is associated with rare copy number variants. PLoS ONE 9(8), e103968 (2014).

37. Anglesio MS, Papadopoulos N, Ayhan A et al. Cancer-associated mutations in endometriosis without cancer. N. Engl. J. Med. 376(19), 1835-1848 (2017).

38. Bulun SE, Monsavais D, Pavone ME et al. Role of estrogen receptor-beta in endometriosis. Semin. Reprod. Med. 30(1), 39-45 (2012).

39. Han SJ, Jung SY, Wu SP et al. Estrogen receptor beta modulates apoptosis complexes and the inflammasome to drive the pathogenesis of endometriosis. Cell 163(4), 960-974 (2015). 
40. Han SJ, O'Malley BW. The dynamics of nuclear receptors and nuclear receptor coregulators in the pathogenesis of endometriosis. Hum. Reprod. Update 20(4), 467-484 (2014).

41. Amaral JD, Sola S, Steer CJ, Rodrigues CM. Role of nuclear steroid receptors in apoptosis. Curr. Med. Chem. 16(29), 3886-3902 (2009).

42. Shi Z, Arai KY, Jin Wet al. Expression of nerve growth factor and its receptors NTRK1 and TNFRSF1B is regulated by estrogen and progesterone in the uteri of golden hamsters. Biol. Reprod. 74(5), 850-856 (2006).

43. Anaf V, Simon P, El Nakadi I et al. Hyperalgesia, nerve infiltration and nerve growth factor expression in deep adenomyotic nodules, peritoneal and ovarian endometriosis. Hum. Reprod. 17(7), 1895-1900 (2002).

44. Bulun SE, Lin Z, Imir G et al. Regulation of aromatase expression in estrogen-responsive breast and uterine disease: from bench to treatment. Pharmacol. Rev. 57(3), 359-383 (2005).

45. Sun HS, Hsiao KY, Hsu CC, Wu MH, Tsai SJ. Transactivation of steroidogenic acute regulatory protein in human endometriotic stromalcells is mediated by the prostaglandin EP2 receptor. Endocrinology 144(9), 3934-3942 (2003).

46. Yoo JY, Kim TH, Fazleabas AT et al. KRAS activation and over-expression of SIRT1/BCL6 contributes to the pathogenesis of endometriosis and progesterone resistance. Sci. Rep. 7(1), 6765 (2017).

47. Zeitoun K, Takayama K, Sasano H et al. Deficient 17beta-hydroxysteroid dehydrogenase type 2 expression in endometriosis: failure to metabolize 17beta-estradiol. J. Clin. Endocrinol. Metab. 83(12), 4474-4480 (1998).

48. Huhtinen K, Desai R, Stahle M et al. Endometrial and endometriotic concentrations of estrone and estradiol are determined by local metabolism rather than circulating levels. J. Clin. Endocrinol. Metab. 97(11), 4228-4235 (2012).

49. Riccio L, Santulli P, Marcellin L, Abrao MS, Batteux F, Chapron C. Immunology of endometriosis. Best Pract. Res. Clin. Obstet. Gynaecol. 50, 39-49 (2018).

50. Reis FM, Petraglia F, Taylor RN. Endometriosis: hormone regulation and clinical consequences of chemotaxis and apoptosis. Hum. Reprod. Update 19(4), 406-418 (2013).

51. Coxon L, Horne AW, Vincent K. Pathophysiology of endometriosis-associated pain: a review of pelvic and central nervous system mechanisms. Best Pract. Res. Clin. Obstet. Gynaecol. 51, 53-67 (2018).

52. Chen DB, Yang ZM, Hilsenrath R, Le SP, Harper MJ. Stimulation of prostaglandin (PG) F2 alpha and PGE2 release by tumour necrosis factor-alpha and interleukin-1 alpha in cultured human luteal phase endometrial cells. Hum. Reprod. 10(10), 2773-2780 (1995).

53. Jabbour HN, Sales KJ, Smith OP, Battersby S, Boddy SC. Prostaglandin receptors are mediators of vascular function in endometrial pathologies. Mol. Cell. Endocrinol. 252(1-2), 191-200 (2006).

54. Tokushige N, Markham R, Russell P, Fraser IS. Different types of small nerve fibers in eutopic endometrium and myometrium in women with endometriosis. Fertil. Steril. 88(4), 795-803 (2007).

55. Wang G, Tokushige N, Markham R, Fraser IS. Rich innervation of deep infiltrating endometriosis. Hum. Reprod. 24(4), 827-834 (2009).

56. Zhang X, Lu B, Huang X, Xu H, Zhou C, Lin J. Endometrial nerve fibers in women with endometriosis, adenomyosis, and uterine fibroids. Fertil. Steril. 92(5), 1799-1801 (2009).

57. Zhang X, Lu B, Huang X, Xu H, Zhou C, Lin J. Innervation of endometrium and myometrium in women with painful adenomyosis and uterine fibroids. Fertil. Steril. 94(2), 730-737 (2010).

58. Morotti M, Vincent K, Brawn J, Zondervan KT, Becker CM. Peripheral changes in endometriosis-associated pain. Hum. Reprod. Update 20(5), 717-736 (2014).

59. Berkley KJ, Rapkin AJ, Papka RE. The pains of endometriosis. Science 308(5728), 1587-1589 (2005).

60. Stratton P, Berkley KJ. Chronic pelvic pain and endometriosis: translational evidence of the relationship and implications. Hum. Reprod. Update 17(3), 327-346 (2011).

61. Ding S, Zhu L, Tian Y, Zhu T, Huang X, Zhang X. P2X3 receptor involvement in endometriosis pain via ERK signaling pathway. PLoS ONE 12(9), e0184647 (2017).

62. Bours MJ, Dagnelie PC, Giuliani AL, Wesselius A, Di Virgilio F. P2 receptors and extracellular ATP: a novel homeostatic pathway in inflammation. Front. Biosci. (Schol. Ed.) 3, 1443-1456 (2011).

63. Whitaker LH, Reid J, Choa A et al. An exploratory study into objective and reported characteristics of neuropathic pain in women with chronic pelvic pain. PLoS ONE 11(4), e0151950 (2016).

64. Fauconnier A, Chapron C. Endometriosis and pelvic pain: epidemiological evidence of the relationship and implications. Hum. Reprod. Update 11(6), 595-606 (2005).

65. Vercellini P, Trespidi L, De Giorgi O, Cortesi I, Parazzini F, Crosignani PG. Endometriosis and pelvic pain: relation to disease stage and localization. Fertil. Steril. 65(2), 299-304 (1996).

66. Howard FM. Endometriosis and mechanisms of pelvic pain. J. Minim. Invasive Gynecol. 16(5), 540-550 (2009).

67. Brawn J, Morotti M, Zondervan KT, Becker CM, Vincent K. Central changes associated with chronic pelvic pain and endometriosis. Hum. Reprod. Update 20(5), 737-747 (2014). 
68. Mcallister SL, Dmitrieva N, Berkley KJ. Sprouted innervation into uterine transplants contributes to the development of hyperalgesia in a rat model of endometriosis. PLoS ONE 7(2), e31758 (2012).

69. Schmidt-Wilcke T, Leinisch E, Straube A et al. Gray matter decrease in patients with chronic tension type headache. Neurology 65(9), 1483-1486 (2005).

70. Schmidt-Wilcke T, Ganssbauer S, Neuner T, Bogdahn U, May A. Subtle grey matter changes between migraine patients and healthy controls. Cephalalgia 28(1), 1-4 (2008).

71. As-Sanie S, Harris RE, Napadow $\mathrm{V}$ et al. Changes in regional gray matter volume in women with chronic pelvic pain: a voxel-based morphometry study. Pain 153(5), 1006-1014 (2012).

72. As-Sanie S, Kim J, Schmidt-Wilcke T et al. Functional connectivity is associated with altered brain chemistry in women with endometriosis-associated chronic pelvic pain. J. Pain 17(1), 1-13 (2016).

73. Millar RP, Zhu YF, Chen C, Struthers RS. Progress towards the development of non-peptide orally-active gonadotropin-releasing hormone (GnRH) antagonists: therapeutic implications. Br. Med. Bull. 56(3), 761-772 (2000).

74. Tucci FC, Zhu YF, Struthers RS et al. 3-[(2R)-Amino-2-phenylethyl]-1-(2,6-difluorobenzyl)-5-(2-fluoro-3-methoxyphenyl)6-methylpyrimidin-2,4-dione (NBI 42902) as a potent and orally active antagonist of the human gonadotropin-releasing hormone receptor. Design, synthesis, and in vitro and in vivo characterization. J. Med. Chem. 48(4), 1169-1178 (2005).

75. Betz SF, Zhu YF, Chen C, Struthers RS. Non-peptide gonadotropin-releasing hormone receptor antagonists. J. Med. Chem. 51(12), 3331-3348 (2008).

76. Chen C, Wu D, Guo Z et al. Discovery of sodium R-(+)-4-\{2-[5-(2-fluoro-3-methoxyphenyl)-3-(2-fluoro-6-[trifluoromethyl]benzyl)-4 -methyl-2,6-dioxo-3,6-dihydro-2H-pyrimidin-1-yl]-1-phenylethylamino butyrate (elagolix), a potent and orally available nonpeptide antagonist of the human gonadotropin-releasing hormone receptor. J. Med. Chem. 51(23), 7478-7485 (2008).

77. Miwa K, Hitaka T, Imada T et al. Discovery of 1-\{4-[1-(2,6-difluorobenzyl)-5-[(dimethylamino)methyl]-3-(6-methoxypyridazin-3-yl)2,4-dioxo-1,2,3,4-tetrahydrothieno[2,3-d] pyrimidin-6-yl]phenyl $\}$-3-methoxyurea (TAK-385) as a potent, orally active, non-peptide antagonist of the human gonadotropin-releasing hormone receptor. J. Med. Chem. 54(14), 4998-5012 (2011).

78. Markham A. Relugolix: first global approval. Drugs 79(6), 675-679 (2019).

79. Osuga Y, Enya K, Kudou K, Tanimoto M, Hoshiai H. Oral gonadotropin-releasing hormone antagonist relugolix compared with leuprorelin injections for uterine leiomyomas: a randomized controlled trial. Obstet. Gynecol. 133(3), 423-433 (2019).

80. Pohl O, Marchand L, Fawkes N, Gotteland JP, Loumaye E. Gonadotropin-releasing hormone receptor antagonist mono- and combination therapy with estradiol/norethindrone acetate add-back: pharmacodynamics and safety of OBE2109. J. Clin. Endocrinol. Metab. 103(2), 497-504 (2018).

81. ObsEva. ObsEva SA announces initiation of Phase 3 EDELWEISS 2 and 3 trials of linzagolix for endometriosis associated pain in U.S., Canada and Europe (2019). http://www.obseva.com/news/obseva-sa-announces-initiation-of-phase-3-edelweiss-2-and-3-trials-of-linz agolix-for-endometriosis-associated-pain-in-u-s-canada-and-europe

82. Zhang N, Shon J, Kim MJ et al. Role of CYP3A in oral contraceptives clearance. Clin. Transl. Sci. 11(3), 251-260 (2018).

83. Struthers RS, Nicholls AJ, Grundy J et al. Suppression of gonadotropins and estradiol in premenopausal women by oral administration of the nonpeptide gonadotropin-releasing hormone antagonist elagolix. J. Clin. Endocrinol. Metab. 94(2), 545-551 (2009).

-• Demonstration of dose-responsive suppression of estradiol with a gonadotropin-releasing hormone antagonist.

84. Ng J, Chwalisz K, Carter DC, Klein CE. Dose-dependent suppression of gonadotropins and ovarian hormones by elagolix in healthy premenopausal women. J. Clin. Endocrinol. Metab. 102(5), 1683-1691 (2017).

85. Winzenborg I, Nader A, Polepally AR et al. Population pharmacokinetics of elagolix in healthy women and women with endometriosis. Clin. Pharmacokinet. 57(10), 1295-1306 (2018).

86. Carr B, Dmowski WP, O’Brien C et al. Elagolix, an oral GnRH antagonist, versus subcutaneous depot medroxyprogesterone acetate for the treatment of endometriosis: effects on bone mineral density. Reprod. Sci. 21(11), 1341-1351 (2014).

87. Crosignani PG, Luciano A, Ray A, Bergqvist A. Subcutaneous depot medroxyprogesterone acetate versus leuprolide acetate in the treatment of endometriosis-associated pain. Hum. Reprod. 21(1), 248-256 (2006).

88. Schlaff WD, Carson SA, Luciano A, Ross D, Bergqvist A. Subcutaneous injection of depot medroxyprogesterone acetate compared with leuprolide acetate in the treatment of endometriosis-associated pain. Fertil. Steril. 85(2), 314-325 (2006).

89. Diamond MP, Carr B, Dmowski WP et al. Elagolix treatment for endometriosis-associated pain: results from a Phase II, randomized, double-blind, placebo-controlled study. Reprod. Sci. 21(3), 363-371 (2014).

90. Ács N, O’Brien C, Jiang P et al. Treatment of endometriosis-associated pain with elagolix, an oral GnRH antagonist: results from a Phase II, randomized controlled study. J. Endometr. Pelvic Pain Disord. 7(2), 56-62 (2015).

91. Carr B, Giudice L, Dmowski WP et al. Elagolix, an oral GnRH antagonist for endometriosis-associated pain: a randomized controlled study. J. Endometr. Pelvic Pain Disord. 5(3), 105-115 (2013).

92. Wyrwich KW, O'Brien CF, Soliman AM, Chwalisz K. Development and validation of the endometriosis daily pain impact diary items to assess dysmenorrhea and nonmenstrual pelvic pain. Reprod. Sci. (25(11), 1567-1576 (2018). 
93. USA FDA. FDA Guidance for industry: patient reported outcome measures. Use in medical product development to support labeling claims (2009). https://www.fda.gov/regulatory-information/search-fda-guidance-documents/patient-reported-outcome-measures-use -medical-product-development-support-labeling-claims

-. The definitive Phase III studies that lead to the US FDA approval of elagolix.

94. Taylor HS, Giudice LC, Lessey BA et al. Treatment of endometriosis-associated pain with elagolix, an oral GnRH antagonist. N. Engl. J. Med. 377, 28-40 (2017).

- Long-term maintenance of efficacy in women with endometriosis treated with elagolix.

95. Surrey E, Taylor HS, Giudice L et al. Long-term outcomes of elagolix in women with endometriosis: results from two extension studies. Obstet. Gynecol. 132(1), 147-160 (2018).

96. Farrar JT, Young JP Jr, Lamoreaux L, Werth JL, Poole RM. Clinical importance of changes in chronic pain intensity measured on an 11-point numerical pain rating scale. Pain 94(2), 149-158 (2001).

-. Describes a potential noninvasive diagnostic for endometriosis.

97. Cosar E, Mamillapalli R, Ersoy GS, Cho S, Seifer B, Taylor HS. Serum microRNAs as diagnostic markers of endometriosis: a comprehensive array-based analysis. Fertil. Steril. 106(2), 402-409 (2016).

98. Tamaresis JS, Irwin JC, Goldfien GA et al. Molecular classification of endometriosis and disease stage using high-dimensional genomic data. Endocrinology 155(12), 4986-4999 (2014).

99. Zondervan KT, Becker CM, Koga K, Missmer SA, Taylor RN, Vigano P. Endometriosis. Nat. Rev. Dis. Primers 4(1), 9 (2018).

•• Gonadotropin-releasing hormone antagonists use for the treatment of bleeding associated with fibroids.

100. Carr BR, Stewart EA, Archer DF et al. Elagolix alone or with add-back therapy in women with heavy menstrual bleeding and uterine leiomyomas: a randomized controlled trial. Obstet. Gynecol. (132(5), 1252-1264 (2018).

101. Archer DF, Stewart EA, Jain RI et al. Elagolix for the management of heavy menstrual bleeding associated with uterine fibroids: results from a Phase IIa proof-of-concept study. Fertil. Steril. 108(1), 152-160.e4 (2017). 
